\title{
Orographic role in anomalous VHF propagation on the background of impending earthquakes
}

\author{
Minakshi Devi ${ }^{1,{ }^{\star}}$, Alaka Medhi $^{1}$, Ananda Kumar Barbara ${ }^{1}$, Anna Depueva $^{2}$, Yuri Ruzhin ${ }^{2}$ \\ ${ }^{1}$ Gauhati University, Department of Physics, Guwahati, India \\ ${ }^{2}$ Pushkov Institute of Terrestrial Magnetism, Ionosphere and Radio Wave Propagation (IZMIRAN), Moscow, Russia
}

\author{
Article history \\ Received December 26, 2014; accepted May 27, 2015. \\ Subject classification: \\ Orography, EQ and VHF anomalous propagation, Earthquake, RRI, Terrain features.
}

\begin{abstract}
The role of orographic factors in modifying atmospheric dynamics on the background of an impending earthquake (EQ) that might lead to propagation of a signal beyond the Line Of Sight (LOS) is examined in the paper. The analysis is based on the data of anomalous reception of VHF FM-signal at Gauhati University (GU, $\left.26.15^{\circ} \mathrm{N}, 91.66^{\circ} \mathrm{E}\right)$, a station located in the sub Himalayan terrain. The signal reception records show that their anomalous appearance are associated closely with earthquake events of $M>5.0$, a phenomenon identified as EQ precursor. To identify sources of such reception, the paper presents some analytical approaches involving the terrain factors, impending $E Q$ and atmospheric variabilities. Finally, the contribution of location/topography of the transmitter, receiver and epicenter in modifying the $E Q$ induced atmospheric factors, is brought in to the ambit of analysis for explaining the observed over horizon VHF signal propagation. A special reference is made on the EQ time drop in temperature, increase in humidity and hence modification in Radio Refractive Index (RRI) gradient, in favoring such reception. A model in support of the observation on EQ time lithosphere-atmosphere coupling relevant to widening of radio horizon limit is also proposed.
\end{abstract}

\section{Introduction}

Troposphere, the lowermost atmosphere is the principal medium of propagation of Very High Frequency (VHF) and microwave signals [Webster and Lam 1980, Lee 1989, Devi et al. 2007, Hayakawa et al. 2007, Serdega and Ivanovs 2007]. It is well established that path of such signals is limited by the Earth's curvature within a zone of nearly $100 \mathrm{~km}$ radius (around the transmitter), known as Line Of Sight (LOS) range or radio horizon. But, modification of this path length might occur due to changes in the refractive index (n) of the atmospheric medium which is generally defined by Radio Refractive Index (RRI) and its gradient. The RRI depends in a complex way on the temperature, humidity as well as on pressure [Smith and Weintraub 1953, Glazier and Lamont 1958, Bean and Duttan 1966,
Dolukhanov 1971, Priestley and Hill 1985]. Therefore, variations in any of these factors may change the RRI and hence the normal radio horizon limits [Bean and Riggs 1959, Dolukhanov 1971, Hall and Bradley 1998]. The factors leading to changes in RRI are strong evaporation, modification in temperature, development of advection and frontal motions which are particularly observed during eruption of volcanoes, prior to occurrence of earthquakes (EQ) and also in growth and development process of a cyclone [Hayakawa and Molchanov 2002, Falodun and Ajewole 2006, Devi et al. 2010b]. A number of reports are also available showing that beyond the horizon propagation of VHF and microwave signal is possible prior to an EQ and such anomalous propagations are associated by many with EQ induced modifications in lower atmospheric parameters [Webster and Lam 1980, Lee 1989, Fukumoto et al. 2002, Devi et al. 2007, Hayakawa et al. 2007, Yasuda et al. 2009].

VHF signal propagation through upper atmosphere of the ionized layer is also possible though its working is different from that of tropospheric mode of Trans reception. In the ionospheric mode, transmitted signal is received at a distant location through total internal reflection in the ionized medium. The maximum frequency reflected by the ionosphere has a limit, known as Maximum Usable Frequency (MUF), the range of which in normal situation is lower than very high frequencies. Therefore, except for some special situations, a VHF signal is not reflected by the ionosphere but escapes into the space. But ionospheric propagations of signals in the VHF range prior to an EQ are also possible as presented by many workers [Gokhberg et al. 1984, Kushida and Kushida 2002, Sakai et al. 2003, Takano et al. 2004, Yasuda et al. 2009, Moriya et al. 2010, Devi et al. 2012].

All these analyses show that factors effecting the EQ time modification in signal propagation character 


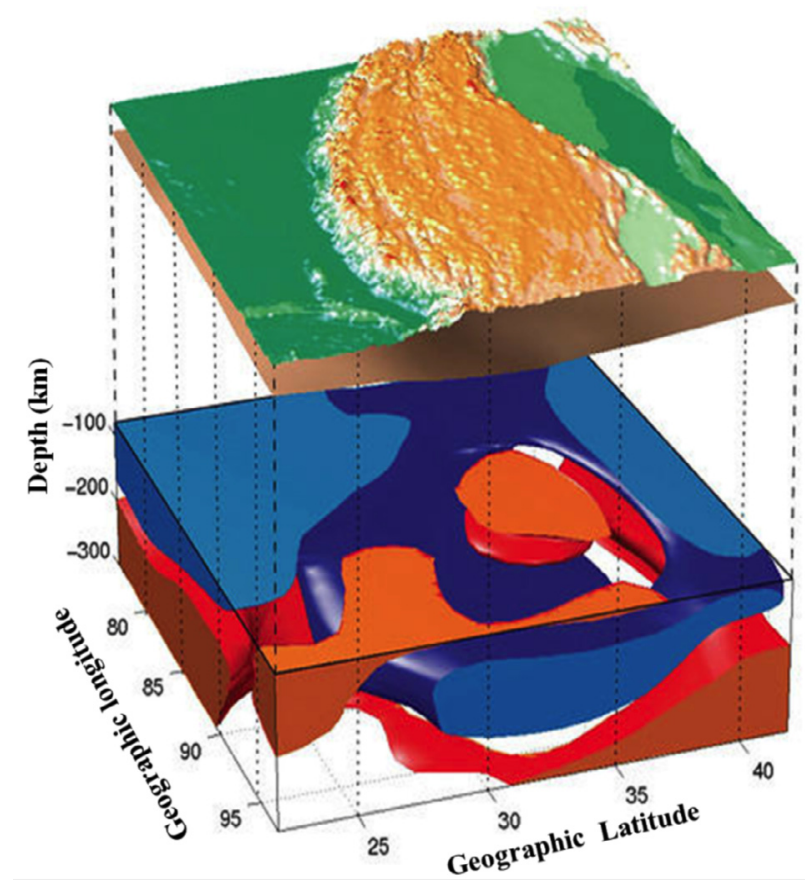

Figure 1. Structure and deformation of the Tibetan lithosphere.

are complex and even with large number of related observations, many aspects still need to be addressed.

The objective of this paper is therefore to understand the role of an EQ-time atmospheric dynamics in a complex topography of sub-Himalayan terrain, leading to beyond the horizon VHF propagation.

\section{Methodology}

For achieving the aims, it is necessary to monitor propagation character of VHF signals from stations beyond the normal LOS path distance. In this exercise our VHF signal source is an FM radio transmitter and receiving station is at Gauhati University, Gauhati (GU, $26.15^{\circ} \mathrm{N}, 91.66^{\circ} \mathrm{E}$, height above the sea level is $55 \mathrm{~m}$ ). The FM transmitting station is selected by taking the following two basic criteria:

i) The distance between transmitting and receiving stations should be out of the normal LOS radius and

ii) One of the stations either transmitter or receiver (or both) falls in the seismically active zone.

Under these considerations with the GU as the receiving centre, the Chukha FM transmitter (frequency $98 \mathrm{MHz})$ of Bhutan $\left(27.05^{\circ} \mathrm{N}, 89.58^{\circ} \mathrm{E}\right.$, height above the sea is around $2 \mathrm{~km}$ ) is found to be suitable for this study. The structure and deformation of the Tibetan lithosphere as presented in Figure 1, justify the selection on the location of FM transmitter.

The receiving set up consists of a 12 element steerable polarized Yagi antenna designed with centre frequency of $90 \mathrm{MHz}$ and is installed at GU, at a height of $6 \mathrm{~m}$ above the ground. The antenna is coupled through matching unit to FM receiving setup with total system gain of $20 \mathrm{db}$. The antenna is though pointed to the transmitter, it is steered for maximum signal strength whenever an unexpected reception even if weak was detected, the channel information logged and signal strength recorded. The antenna is also switched between horizontal to vertical modes, for exploring if reception quality improves. Whenever an EQ event around the trans-receiving zone is identified, the atmospheric variables like temperature, humidity, pressure at the ambit of influence of the epicenter are analyzed in association with magnitude of the received signal. The ionospheric parameter like the Total Electron Content (TEC) continuously recorded at GU and electron content data available from global monitoring systems are also adopted as supporting inputs whenever necessary.

\section{Analysis and results}

\subsection{Anomalous signal strength and temperature variation}

The magnitude of the received signal (if any) from the distant transmitter at Chukha is monitored round the clock at GU and its mean value for each day is calculated. Figure 2 displays signal magnitude variations for a period from September 2012 to September 2013. Of interest is the sudden appearance of two events (we will mark these as October event of 2012 and January event of 2013) with significant increase in received signal levels as identified by arrow heads in the figure. The basic aspects that will be analyzed in explaining such reception are: (i) signal appearance features, (ii) occurrence of EQ event (if any) and (iii) atmospheric ambiances during that time.

We will first examine the January 2013 event, because of the strong anomalous signal received in this case compared to that of the October event. For this purpose, the routine records of signal magnitudes for

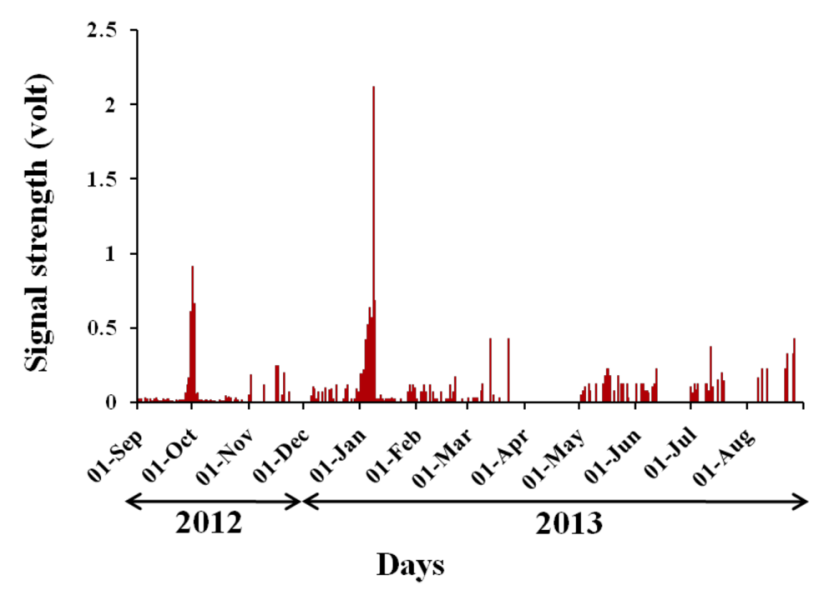

Figure 2. Signal strength (volts) received at GU, from the Chukha FM transmitter for the period September 2012 to September 2013. The two events marked by arrow heads show sudden appearance of relatively strong signals. 
the period from December 2012 to February 2013, covering anomalous reception event of January 2013, are displayed in Figure 3. One can note a sudden increase of signal from January 2 to January 8, 2013, and its disappearance, once its strength had reached the peak on January 8. Significantly, the signal was received only in horizontal polarization position of the antenna and no reception in its vertical counterpart was noted.

To identify what forces were behind this anomalous reception, the seismic records with special references to the epicenter positions (within the trans-receiving zone) are examined. In this regard, the EQ of January 9,2013 , at $25.4^{\circ} \mathrm{N}, 94^{\circ} \mathrm{E}(\mathrm{M}=5.9$; depth about $75 \mathrm{~km})$ i.e., $235 \mathrm{~km}$ form $\mathrm{GU}$ was identified as a potential source. Therefore, role of this EQ in modifying atmospheric variabilities like temperature and humidity at the epicenter and receiving station on the background of the topography of the relevant zone (presented in Figure 4) is then explored.

The temperature records near the epicenter for the EQ of January 9 and at receiving site are analyzed and maximum temperature (Tmax) of each day for the month is extracted from the respective profile. However, temperature being an involved parameter with background factors, its day to day variation is expected even in a normal situation. It is therefore essential to determine normal diurnal maximum excursion levels of Tmax, before identifying its earthquake-time variations. This necessity requires temperature data to be processed and filtered. For this purpose standard deviation $(\sigma)$ of Tmax in normal day situation is calculated for defining maximum and minimum possible excursions of Tmax, which are $\sigma+\operatorname{Tmax}$ (mean) and $\sigma-\operatorname{Tmax}$ (mean) where Tmax (mean) is the mean value of maximum temperature for the month. Deviation of Tmax from this excursion limits will be treated as anomalous.

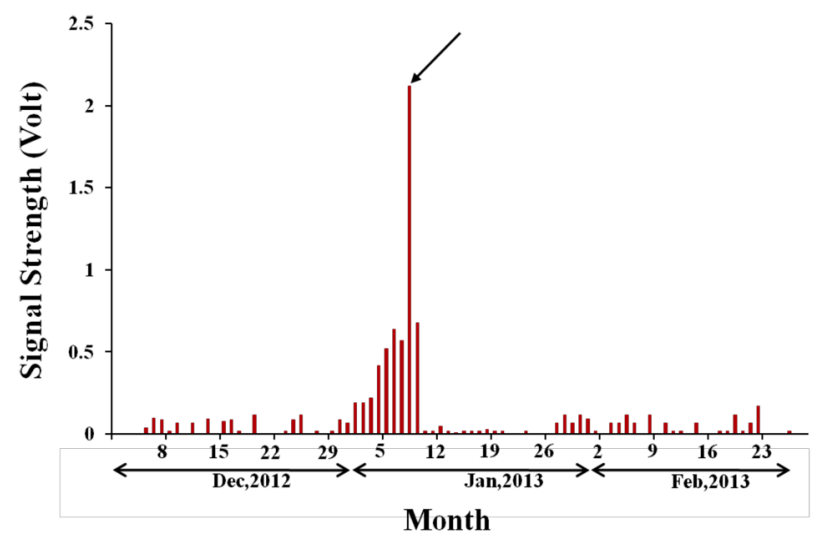

Figure 3. Signal strength (volts) received at GU, from the Chukha FM transmitter for the period December 2012 to February 2013. Note the sudden appearance of the signal from January 2 to January 8 . The arrow mark shows the day (January 8 ) when signal strength reaches its peak.

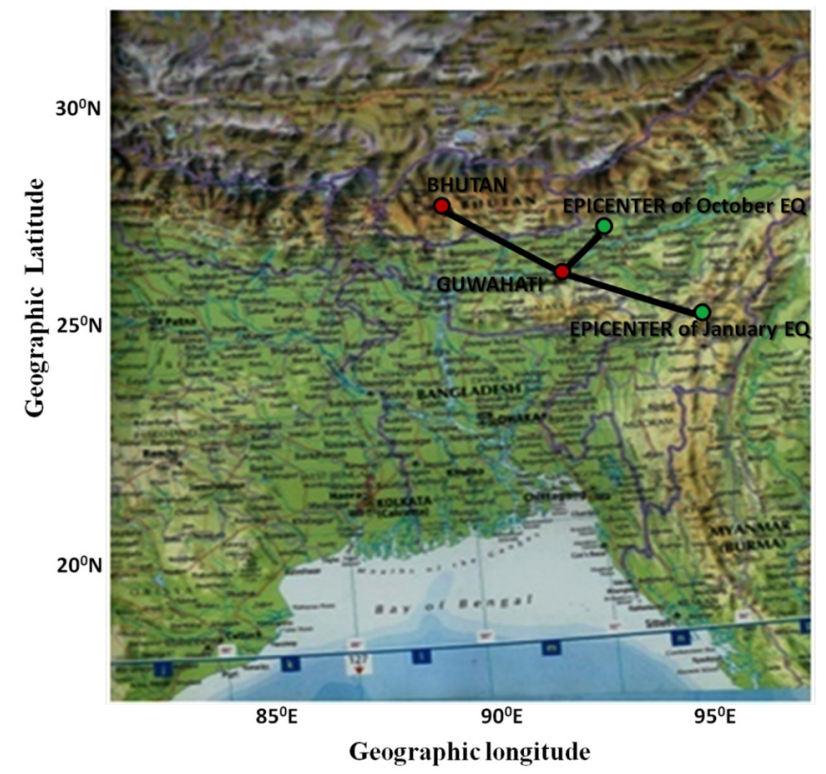

Figure 4. Map showing transmitter (at Bhutan) and receiver (at Guwahati) locations (red circle); the epicenter positions are marked by green circles.

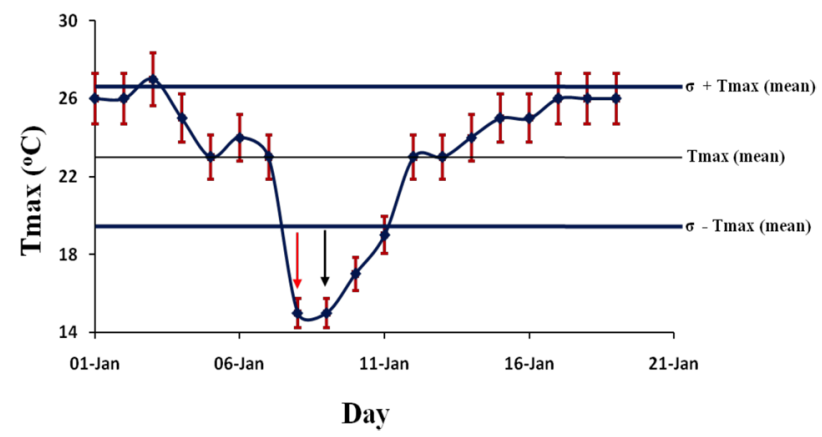

Figure 5. Day to day variations of the maximum temperature Tmax from January 1 to January 19, 2013, recorded at the epicenter site for the January 9, 2013, EQ event. The standard deviation magnitude of Tmax from the average values is shown by thick blue lines. The day of attaining a sudden minimum in temperature (January 8, 2013), is marked by red arrow head while the black arrow shows the EQ day.

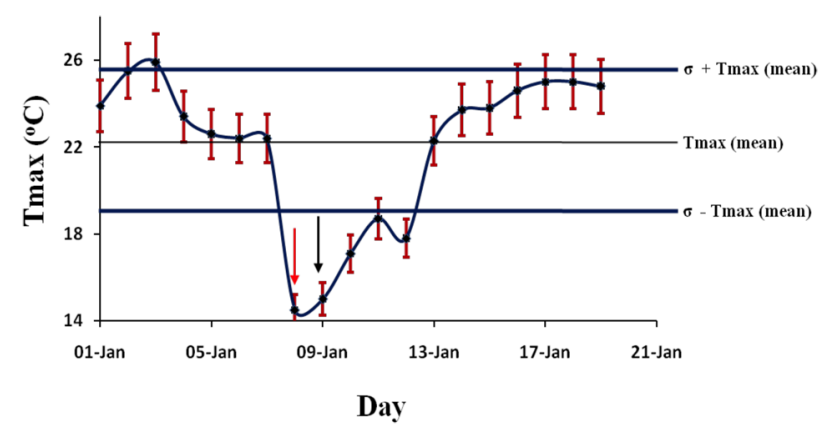

Figure 6. Day to day variations of the maximum temperature (Tmax) from January 1 to January 19, 2013, recorded at GU. The standard deviation magnitude of Tmax from the average values is shown by thick blue lines. The day of attaining a sudden minimum in temperature is marked by red arrow head while the black arrow shows the EQ day. 


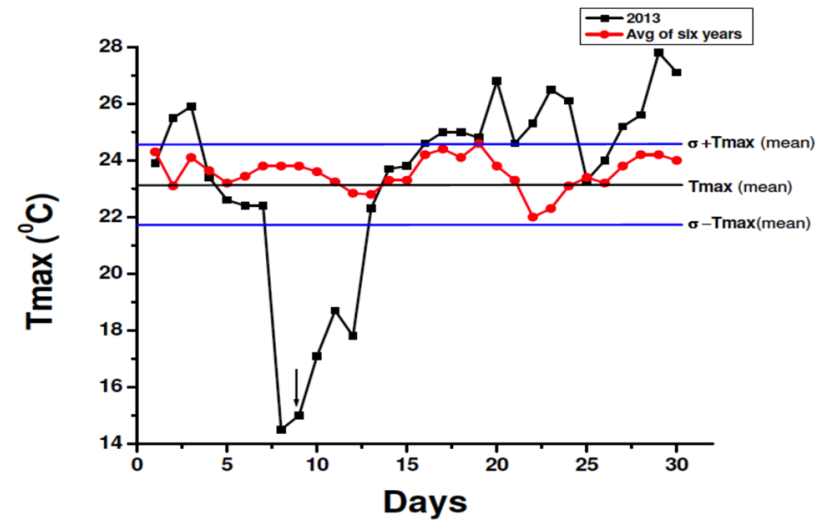

Figure 7. Six years average maximum temperature variation (Tmax) for January along with that for January 2013, observed over Guwahati. Note the large drop in temperature prior to the January 2013 EQ. The EQ day is marked by an arrow head. The standard deviation magnitude of Tmax from the average values is shown by thick blue lines.

In Figure 5 day to day variations of Tmax near the epicenter of the January 9 EQ with $\sigma \pm$ Tmax (mean) are shown (thick lines). The figure displays a sudden and brief increase of temperature about six days prior to the event followed by its gradual decrease reaching a minimum on January 8 , a day before the occurrence of the EQ.

Correspondingly, a similar variation in Tmax recorded at the GU site is also observed in January 2013, as displayed in Figure 6. One can see that after a short increase in temperature about a week before the EQ, it starts decreasing to reach a value of around $15^{\circ} \mathrm{C}$ on January 8 , which is lower by $8^{\circ} \mathrm{C}$ from the average Tmax value. The recovery of temperature to the average level also takes 4-5 days after the EQ (Figure 6). To assess the confidence level of the pre-EQ time temperature anomaly, the day to day variation of Tmax for the month of January 2013 is plotted in Figure 7 along with the corresponding six years (2006-2011) average Tmax value for the earthquake free month of January. The abnormal decrease in temperature on January 8, 2013, is unique and significant. It is further noted that along with changes in the Tmax value, a drastic modification in the entire diurnal profile of the temperature status especially on January 8 is noted at GU as shown in Figure $8 \mathrm{a}$. On this day the normal increase in temperature after sunrise is suddenly reversed at 1100 hours, $82.5^{\circ}$ EMT, and it continues to decrease reaching an abnormal minimum (Figure 8a) at 1130 hours, $82.5^{\circ}$ EMT. Followed by a slow recovery from this point, the temperature then starts increasing to attain a maximum of $16^{\circ} \mathrm{C}$, (at 1345 hours, $82.5^{\circ}$ EMT) a value still lower by $40 \%$ from the average. The diurnal humidity profile (Figure 8a) also reflects such anomaly on this day, when an abrupt increase in its value to $70 \%$ from its normal figure of $60 \%$ to $64 \%$ is detected during $1100-1200$ hours, $82.5^{\circ}$ EMT. These unusual variations are marked within a box in the temperature/humidity plot of Figure 8a. However, these features are not seen either on the preceding (Figure $8 \mathrm{~b}$ ) or the following day of January 8 (Figure $8 \mathrm{c}$ ). It is a significant point to note that on January 8 the strength of over horizon signal reaches its peak (Figure 3), while relatively weak signal was received at GU, both on January 7 and 9.

The over horizon signal reception character during the October event of 2012, is next presented and analyzed in the light of the January event of 2013. In this case the signal from Chukha station appears from September 26, attaining maximum on October 1, 2012, and then fades out as shown in Figure 9. The seismic records
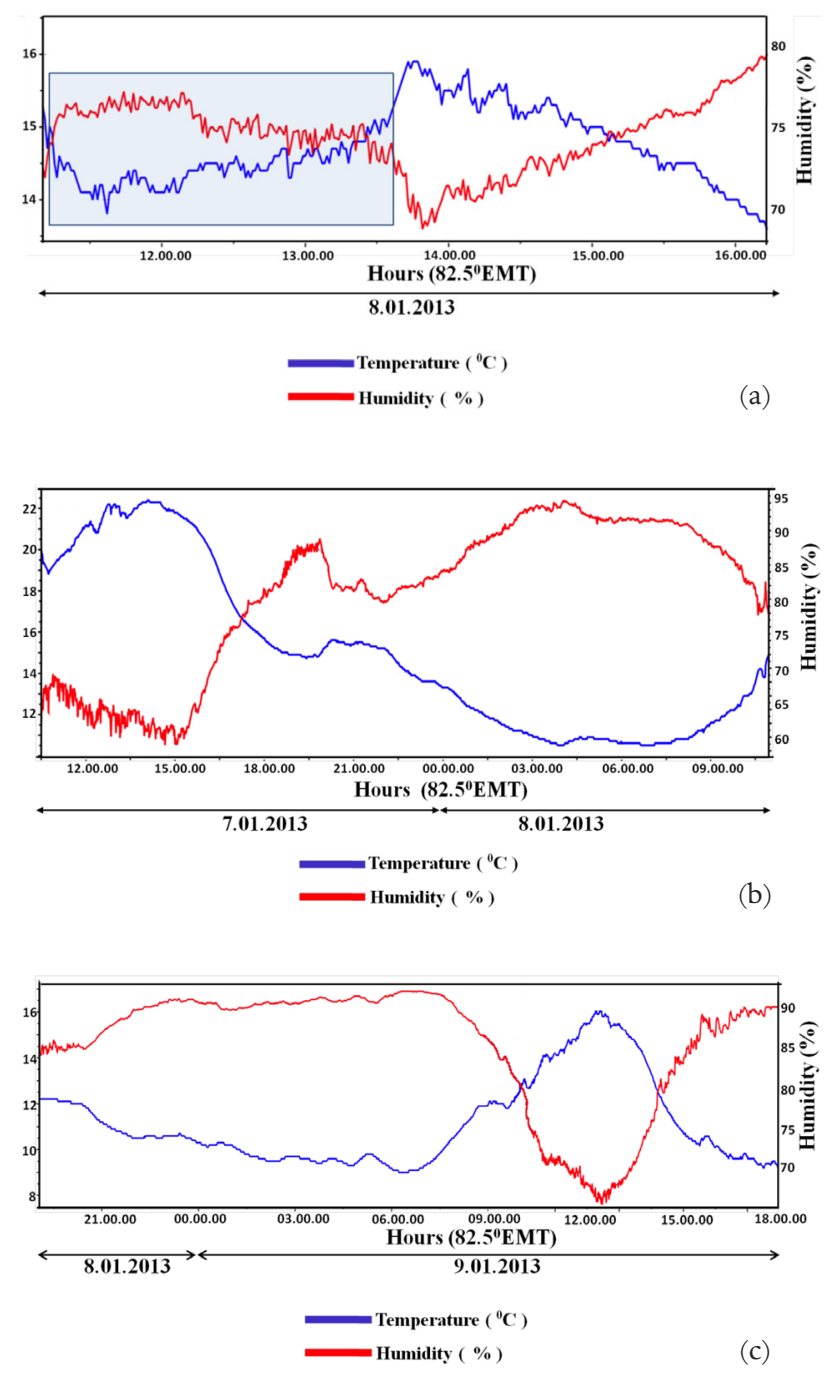

Figure 8. (a): Unusual temperature and humidity features recorded at GU during 1100 hours to 1630 hours of January 8, 2013, a day prior to the January EQ event. The sudden drop in temperature at 1130 hours, $82.5^{\circ} \mathrm{EMT}$ is to be noted along with the increase in humidity. These anomalous features are marked within a box in the temperature/humidity plot. (b) and (c): Normal variations in temperature and humidity a day preceding (1100 hours, $82.5^{\circ}$ EMT of January 7 to 1000 hours, $82.5^{\circ}$ EMT of January 8) and a day after (1800 hours, $82.5^{\circ}$ EMT of January 8 to 1800 hours, $82.5^{\circ}$ EMT of January 9) the unusual event recorded on January 8. 
reveal occurrence of an earthquake on October 2, 2012, at $26.9^{\circ} \mathrm{N}$ and $92.8^{\circ} \mathrm{E}$ with $\mathrm{M}=5.1$ and depth $=35 \mathrm{~km}$ (Figure 4, distance $144.7 \mathrm{~km}$ from GU), i.e., one day after the maximum signal strength was received from Chukha station (Figure 9), a similar feature as of January event of 2013. The day to day variations of Tmax for the October EQ were next examined at the epicenter site and at GU and corresponding $\sigma \pm$ Tmax value was calculated as described earlier. The analysis outputs obtained from the two sites for the period from 25 September 25, 2012, to October 7, 2012, covering the EQ day, as presented respectively in Figures 10a and 10b display a short-time initial increase in temperature prior to three or four days of the EQ, followed by a decrease reaching a minimum on the day of the event i.e., on October 2.

3.2. Association of atmospheric parameters with anomalous signal amplitudes received in cases of this study

To examine association between temperature, humidity and beyond the radio horizon signal strength, the day to day percentage deviations in maximum temperature ( $\delta$ Tmax) and humidity ( $\delta$ Hmax) from their monthly average values are calculated.

Figure 11 displays the result of above associationanalysis for the period from January 1 to 16,2013 , covering the EQ-day of January 9, 2013. One can see that with the increase of signal strength by $1000 \%$ on January 8 , the humidity shows enhancement by $30 \%$ in synchronization with the decrease of temperature by $40 \%$.

For the October 2012 EQ too, the variations of the received signal strength, temperature and humidity measured at GU show a similar pattern (Figure 12) as of the January 2013 earthquake case. The synchronization in time of attaining maximum in signal strength and in humidity with the time of reaching minimum temperature around the EQ days is significant.

3.3. Possible mode of propagation of over horizon signal

In the two cases presented here, it is seen that the distance between the transmitter and receiving station is beyond the LOS range but is less than $300 \mathrm{~km}$ and the signal were received only in horizontal polarization mode of the antenna. It is also noted from the reported results of many workers [Sakai et al. 2003, Takano et al. 2004, Devi et al. 2012] that mode of propagation of frequencies of wave length $\lambda>4-6 \mathrm{~m}$, is generally through ionospheric $F$ layer or by sporadic $E$ layer, but for $\lambda<4 \mathrm{~m}$ as in the present case, the reflection through ionosphere is not expected. This aspect can be further substantiated on computing the maximum possible frequency $\left(\mathrm{f}_{\max }\right)$ that can be reflected by the ionosphere in

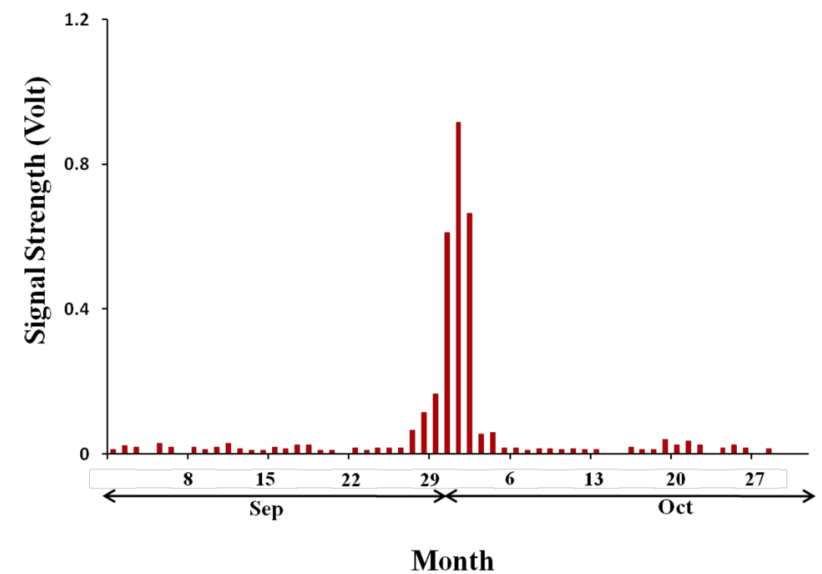

Figure 9. Signal strength (volts) received at GU, from the Chukha FM transmitter for the period September 2012 to October 2012. Note the sudden appearance of the signal from September 28, reaching peak on October 1, 2012 (marked by black arrow head).
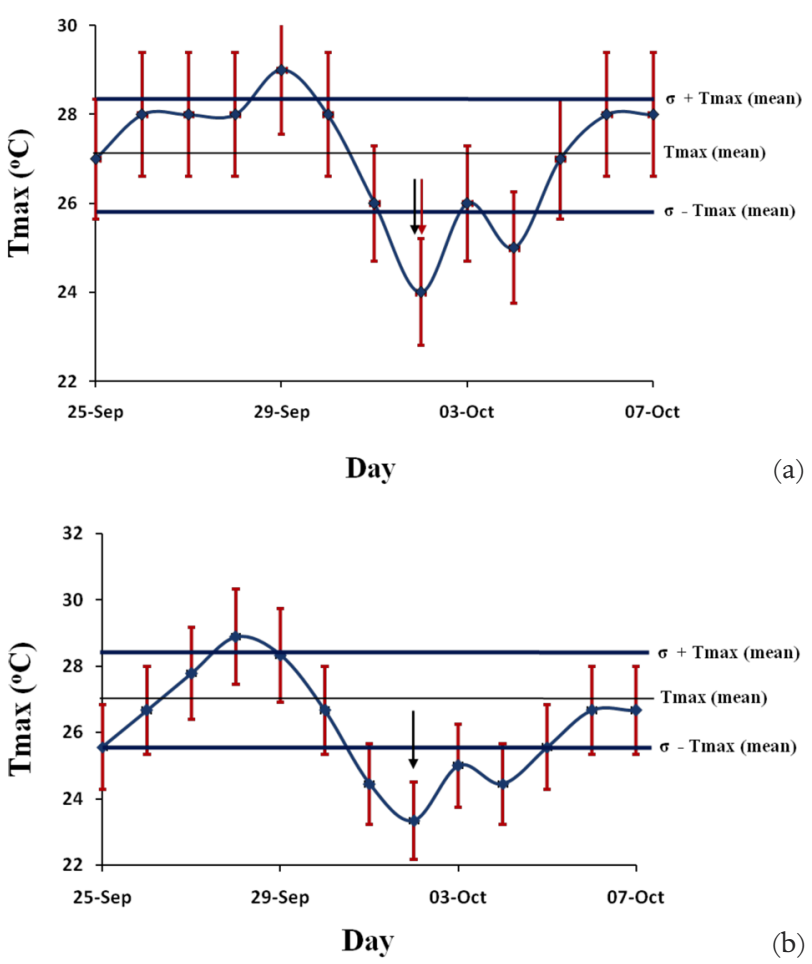

Figure 10. Day to day variations of the maximum temperature (Tmax) from September 25, 2012, to October 07, 2012, recorded at the (a) epicenter site and (b) at GU, during October 1, EQ event. The standard deviation magnitude of Tmax from the average values is shown by thick blue lines. The day of attaining a sudden minimum in temperature is marked by red arrow head while the black arrow shows the EQ day.

the context of signal transmitted by the Chukha transmitter. For this purpose $f_{\text {max }}$ is calculated for different propagation angles by using Equation (3.1):

$\mathrm{f}_{\text {max }}=$

$\left.\sqrt{ }\left[\left\{80.8 * 2 \times 10^{6}(1+(2 \mathrm{~h} / \mathrm{a}))\right]\right\} /\left\{\sin ^{2} \mathrm{~B}+(2 \mathrm{~h} / \mathrm{a})\right\}\right]$

where $h$ is the ionospheric height, 'a' the radius of the 

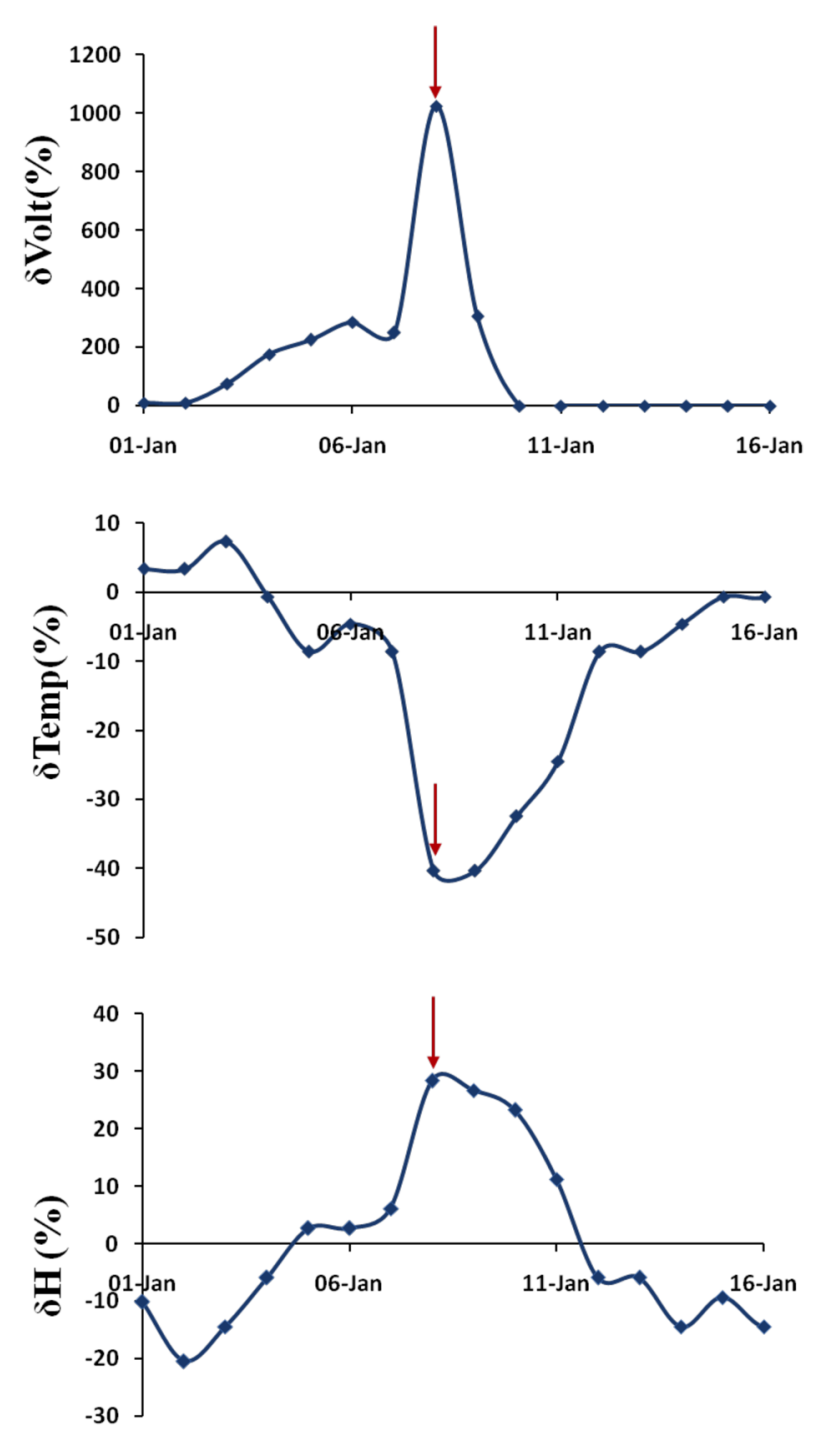

Figure 11. Percentage increase in magnitudes of over horizon signal amplitudes (in volt) observed at GU for the days covering January 9, 2013, EQ event, along with deviations of temperature and humidity from the average magnitude. Note that with the increase of signal strength by $1000 \%$ on January 8 , the humidity shows enhancement by $30 \%$, in synchronization with the decrease of temperature by $40 \%$. The red arrow marks the simultaneity between these events, on January 8.

Earth and $B$ is the propagation angle.

Results show that the maximum possible frequencies incident at a lowest grazing angle of $0.1^{\circ}$ that may propagate by ionospheric reflections at heights of 300 $\mathrm{km}, 200 \mathrm{~km}$ and $100 \mathrm{~km}$ are respectively $25 \mathrm{MHz}, 32$ $\mathrm{MHz}$ and $42 \mathrm{MHz}$, suggesting that $98 \mathrm{MHZ}$ signals from Chukha station cannot flow to GU through ionosphere. But ionospheric reflection from altitudes below $100 \mathrm{~km}$ may still be possible especially at the EQ time anomalous ambiance. This is because of extension of ionosphere to the lower reaches during an EQ which is associated with ionization by radon emission [Harission et al. 2010] and EQ-time thunder generated density [Piša et al. 2013]. Devi et al. [2010a] have also suggested
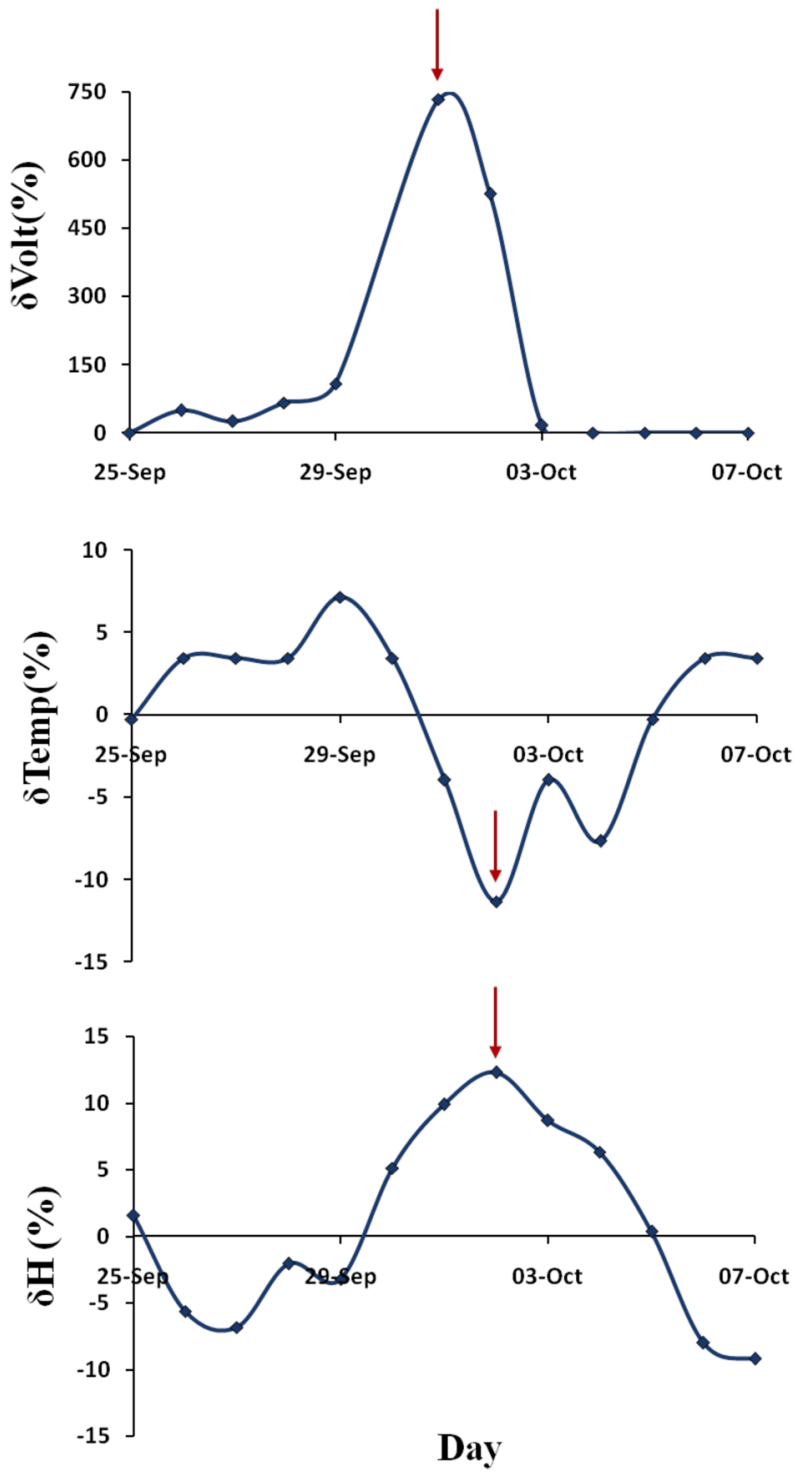

Figure 12. Percentage increase in magnitudes of over horizon signal amplitudes (in volt) observed at GU for the days covering the October 1, 2012, EQ event, along with deviations of temperature, humidity from the average magnitude. Note that with the increase of signal strength by $700 \%$, the humidity shows enhancement by $12 \%$, in synchronization with the decrease of temperature by $10 \%$. The red arrow marks the simultaneity between these events.

induction of ionization at lowest ionospheric altitudes during an EQ, while computing seismic time TEC profiles by adopting IRI model. Therefore, taking the situation when lower reaches of the ionosphere (with relatively large ionization density) might move down to $80 \mathrm{~km}$, by the EQ preparatory processes, the maximum usable frequencies may be increased to $45 \mathrm{MHz}-50$ $\mathrm{MHz}$ at the lowest grazing propagation angle, but not beyond.

Considering these aspects along with horizontal mode of signal reception and EQ-time atmospheric status, we conclude that the anomalous propagation of signal in the present cases is through troposphere but not by ionospheric scattering or reflection. 


\section{Discussion}

Over horizon propagation of signal prior to an earthquake is not a new finding [Kushida and Kushida 1998, Pilipenko et al. 2001, Fukumoto et al. 2002, Devi et al. 2007, Hayakawa et al. 2007, Devi et al. 2012]. But each case provides new information relevant to system physics and dynamics. Anomalous reception of FM radio programme is associated by some scientists [Kushida and Kushida 1998, 2002] with scattering by ionospheric perturbations triggered by EQ, whereas beyond the LOS FM reception is related by others with tropospheric scattering [Fukamato et al. 2002, Yasuda et al. 2009].

Takano et al. [2004] suggested that 48.25 MHz long distance TV reception obtained by them from a distance of $5200 \mathrm{~km}$ was due to the reflection from the F-layer and the $49.75 \mathrm{KHz}$ signal received at $1800 \mathrm{~km}$ distance was from sporadic E-layer. Working with reception of TV signals, this group of workers [Devi et al. 2007] had offered a model of complex mode of propagation in frequency range of $54 \mathrm{MHz}-70 \mathrm{MHz}$ to distances thousand $\mathrm{km}$ and beyond, by involving both the EQ time modification in the ionosphere and troposphere. In the present cases the troposphere plays the significant role in propagation of over horizon signal; therefore, a brief discussion related to possible modification in this layer by external sources other than the sun and its gamut of radiation frequencies, is presented now.

It is well known that the LOS tropospheric propagation is controlled by the refractive index $n$ of the medium that decreases slightly with altitude. Therefore, a ray travelling through the troposphere is refracted and bends towards the Earth, this curvilinear path is equivalent to a straight line path over an Earth surface with a variable radius of curvature depending on the status of the troposphere. Therefore, a parameter called effective Earth's radius $\mathrm{a}_{\mathrm{e}}$ is introduced, and the ratio of $\mathrm{a}_{\mathrm{e}}$ to true Earth radius ' $\mathrm{a}$ ', is given by: $\mathrm{k}=$ $\mathrm{a}_{\mathrm{e}} / \mathrm{a}$. In normal atmospheric situations when $\mathrm{k}=4 / 3$, the ray curvature gives the standard field of view of line of sight propagation links. But with changes of refractive index, the path geometry gets modified and propagation of signal beyond the normal view of the trans-receiver link is possible. However, change of $n$, being very small, this is designated by a factor $\mathrm{N}=$ $(n-1) \times 10^{6}$, the Radio Refractive Index (RRI) and its gradient $\mathrm{dN} / \mathrm{dh}$ with height $\mathrm{h}$. The RRI depends on the temperature, humidity and pressure in a complex relation as given by Equation (4.1) and the relation of RRI gradient with $\mathrm{k}$ is expressed by Equation (4.2)

$\mathrm{N}=(\mathrm{n}-1) \times 10^{6}=(77.6 \mathrm{P}) / \mathrm{T}+(375000 \mathrm{e}) / \mathrm{T}^{2}$

$\mathrm{k}=\mathrm{a}_{\mathrm{e}} / \mathrm{a}=1 /(1+\mathrm{a} \mathrm{dN} / \mathrm{d} h)$
Any change in RRI/ $\mathrm{km}$ from the normal-value will increase or decrease radio link hops. Thus, the magnitude of $\mathrm{dN} / \mathrm{d} h$ determines the prevailing atmospheric propagation status. Here P in the Equation (4.1) denotes atmospheric pressure, $\mathrm{T}$ gives dry temperature while the wet term e is sensitive to humidity i.e., changes of air mass with height, so the RRI depends on height of the transmitting and receiving stations. Further, local environments and climatic scenario have significant influences on RRI and therefore on the LOS path length [Bean and Rigg 1959, Sheer 1961, Valma et al. 2011]. Therefore, status of communication between two stations needs to be examined with all these factors in to account, a discussion in this regard is presented in the following section.

In general, the geometry of the transmitter $(\mathrm{Tx})$ and receiver station $(\mathrm{Rr})$ dictates the maximum signal propagation distance possible between the $\mathrm{Tx}$ and $\mathrm{Rr}$ and this distance dmax occurs when the direct ray is tangential to Earth surface.

The Region of direct VHF radio illumination by Bhutan transmitter (height $\mathrm{h}=2000 \mathrm{~m}$ ) is $\mathrm{R}_{\mathrm{t} 0}=$ $3.55^{*} \mathrm{~h}^{-1 / 2}=159 \mathrm{~km}$.

Now, considering the normal tropospheric condition with $\mathrm{k}=4 / 3$, and the transmitter and receiver location status, the maximum possible LOS distance dmax for radio waves between Chukha and GU is found by Equation (4.3)

$d \max =\sqrt{ } 2 a_{e} h_{1}+\sqrt{ } 2 a_{e} h_{2}$

Here $a_{e}$, corresponds to effective radius of the Earth for normal time tropospheric RRI conditions and $h_{1}, h_{2}$ are the heights of the considered transmitter and receiver antenna from Earth surface respectively.

The calculation shows that dmax lies at $206 \mathrm{~km}$. Therefore with normal tropospheric curvature with $\mathrm{k}=$ $4 / 3$ condition, a signal from the Chukha is not expected to be received at GU situated at around $245 \mathrm{~km}$ distance. The value of $\mathrm{k}$ or of $\mathrm{a}_{\mathrm{e}}$, required for generating a favorable tropospheric condition for a radio signal to cover the distance between Chukha and GU, is presented in Table 1. It is seen that for attaining the required tropospheric status, the value of, $\mathrm{a}_{\mathrm{e}}$ needs to be increased by 1.5 times or by $18 \%$ from the normal day tropospheric value. In this condition the RRI gradient goes to $-80 \mathrm{~N} / \mathrm{km}$ (Equation 4.2), for favoring propagation of over horizon signal. This result suggests that on the days when signals from Chukha were received at GU, the RRI should reach at least a value of $-80 \mathrm{~N} / \mathrm{km}$. We therefore calculate RRI over GU from the Equation (4.1), (with the observed parameters) and the received gradient of $-80 \mathrm{~N} / \mathrm{km}$ up to $1.0 \mathrm{~km}$ height on January 8 , 


\begin{tabular}{cc}
\hline $\begin{array}{c}\text { Effective } \\
\text { Earth radius } \mathrm{a}_{\mathrm{e}} \\
(\mathrm{km})\end{array}$ & $\begin{array}{c}\text { Maximum } \\
\text { wave distance }(\mathrm{km}) \\
\text { for the transmitter } \\
\text { at Chukha, Bhutan } \\
\text { and receiver } \\
\text { at GU, Guwahati }\end{array}$ \\
\hline 8533 & 194 \\
8960 & 199 \\
9387 & 204 \\
9600 & 206 \\
10,027 & 211 \\
10,667 & 217 \\
11,308 & 224 \\
12,160 & 232 \\
12,800 & 238 \\
13,013 & 240 \\
13,227 & 242 \\
13,440 & 244 \\
13,653 & 246 \\
13,867 & 249 \\
14,720 & \\
\hline
\end{tabular}

Table 1. The effective Earth radius and corresponding maximum wave distance relevant to the Trans- receiver location status, considered in the study. Note that only when effective Earth radius factor goes around 13,400 km (i.e., when $\mathrm{dN} / \mathrm{dh}=-80 \mathrm{~N} / \mathrm{km}$ or more negative) reception of signal from Chukha, station is expected to reach Guwahati, a condition obtained prior to the considered EQ events.

2013, supports generation of a favourable situation leading to anomalous propagation of signal. In October 2012 EQ event too, the observed RRI gradient of $-70 \mathrm{~N} / \mathrm{km}$ is an index of possible increase of over horizon propagation path length.

Further, it is essential to estimate the effective preparatory radius of the EQ, and its contribution to the increase in LOS path and hence in anomalous signal reception. In case of the January EQ, the following calculation is made to examine whether propagation path lies within the EQ preparatory process.

Here, the size of earthquake preparation zone according to Dobrovolsky formula comes as $\mathrm{R}_{\mathrm{EQ}}=\mathrm{e}^{\mathrm{M}}=$ $\mathrm{e}^{5.9}=365 \mathrm{~km}$ (marked by circle in Figure 13).

It is seen from geometry that distance between epicentre of January 2013 EQ and Bhutan is $475 \mathrm{~km}$, the distance of GU w.r.t epictre is $248 \mathrm{~km}$ and therefore the effective preparatory zone of $365 \mathrm{~km}$ covers a significant part (estimated as $45 \%$ ) of the propagating path between Chukha to GU. The simple geometry thus shows that Bhutan-GU epicentre locations are on the same straight line and significant part of VHF radio propagation was inside the region under the preparatory action of the earthquake. The parameters like temperature and humidity also get modified in this process. Such VHF trace is thus very convenient for registration of anomaly due to pre seismic regional activity. Similarly we can see that in the October 2012 EQ case, only $8 \%$ of the propagating path is intercepted by the active EQ preparatory circle. As the LOS reception of a radio signal is affected by cumulative bending of the ray due to the refraction over the entire signal path [Onoe et al. 1958], modification in refractive index in any section of the path will leave its own imprint on the path length. Therefore, reception of relatively strong anomalous signal on the January event, compared to that of the October EQ case, is now apparent, though Chukha transmitter and epicenter of the January EQ (at Indo-Myanmar border) lies just in opposite directions about GU (Figure 4). This observation points to the fact that the beyond the horizon propagation of signal at EQ-times may be expected even when the transmitter and epicenter locations are in opposite direction relative to the receiver so long the propagation trajectory is intercepted by the EQ preparatory radius.

Along with these aspects, one can also bring in to discussion the possible role of aerosols of the lower atmosphere in favouring VHF anomalous propagation. Sorokin et al. [2014] have shown through model computation that discharges in ionized layer formed at $6 \mathrm{~km}$ to $10 \mathrm{~km}$ by charged aerosols due to lifting of soil gases over seismic region, could help VHF signal to enhance its LOS range. However, in our case with the transmitter-receiver epicenter location geometry, the model could

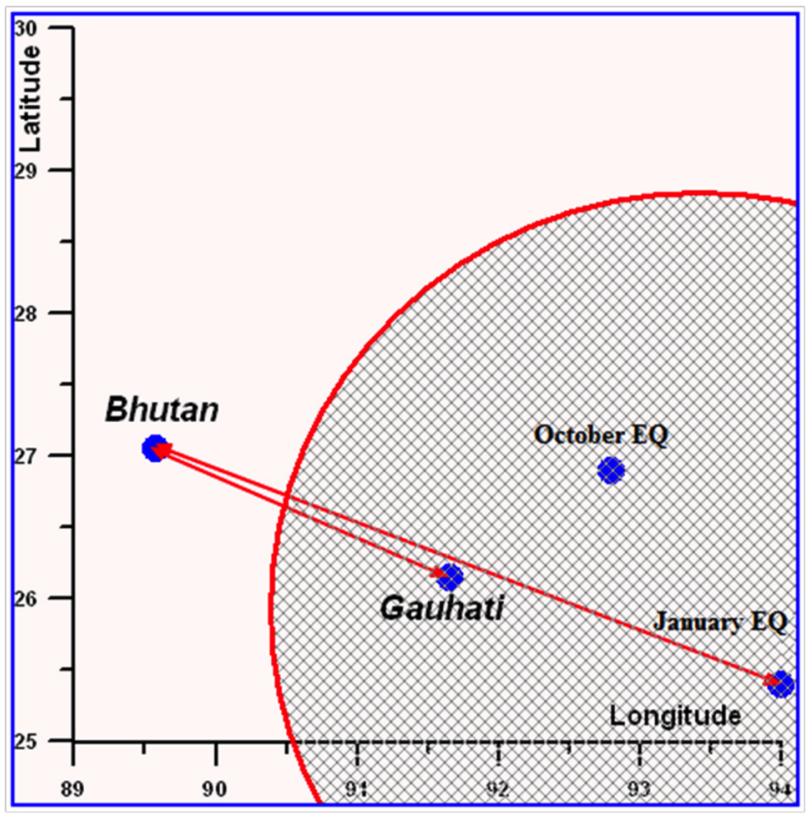

Figure 13. The earthquake preparatory zone of January 9, 2013, $\mathrm{EQ}$ and the simple geometry of Bhutan-GU and epicenter locations. 
not be fitted into the observed signal reception pattern. These include observation of no noise in the background prior to the events and requirement of near vertical striking angle at the discharge zone.

It is however important to examine association of orographic role on EQ time changes in atmospheric dynamics in enhancement of LOS path length in the environment taken under this study. This indeed is a difficult task as earthquake preparatory processes could cause diverse effects in the near Earth space and their manifestations are observed at the surface that may extend even up to the ionosphere [Depueva and Ruzhin 1995, Devi et al. 2001, Liu et al. 2001, Devi et al. 2004, Parrot et al. 2008, Devi et al. 2011, Devi and Barbara 2012, Devi et al. 2013a, Devi et al. 2013b, Parrot et al. 2013]. However, in the context of present observation, the atmospheric factors with reference to EQ-time drop in temperature will be specially discussed as this is one of the prime factors leading to changes in near Earth dynamics and also that in almost all the reported cases related to EQ induced temperature variations, be it surface temperature, the Sea Surface Temperature (SST) or Surface Latent Heat Flux (SLHF) [Qiang 1997, Tronin 2000, Tronin 2002, Dey and Singh 2003, Cervone et al. 2004, Devi et al. 2007, Ouzonov et al. 2007, Singh et al. 2007, Alvan et al. 2012, Goswami et al. 2014], an increase in its value has been noted except a few cases [Singh et al. 2010]. Such enhancement in temperature is related to the strain that affects its fluid-rock interaction releasing radiation from Ultra Low Frequencies (ULF) to Infra Red (IR) especially along the fault zone. Our observations of drop in temperature during the EQ cases cannot therefore be explained only by above factors and it is necessary perhaps to include the dynamic status of the atmosphere dictated by the associated terrain topography of the transmitting and especially of the receiving zone. One significant point to be noted from Figures 4, 5 and 9 is that a decrease in temperature follows its increase, even for a small period of time (one day). Such reduction in temperature therefore might in fact be the result of initial increase in ambient temperature (warming the atmosphere of a localized area caused by emission of heat energy through weak fault line), which is then cooled by air from the surrounding low temperature zones. One such sources of cold air around the study zone during the winter is North Easterly (NE) wind (Figure 14), when the land is cooler than the Bay of Bengal (BOB). The sudden increase and accumulation of EQ time temperature generates a circulation, leading to a localized low pressure area which may immediately be replenished by the cold $\mathrm{NE}$ wind prevailing during this season as displayed in Figure 14, by the wind direction obtained from the model VARSHA. Such process will not only check the temperature growth process but may lower the temperature from the average as observed in the study. This process is augmented by the local environments of the epicenter and surroundings as can be seen from circulation of wind in the NE part of India (Figure 14). These modifications are therefore reflected in the RRI values as observed prior to the January EQ favoring VHF anomalous propagation.

For the October EQ, the warm localized circulation and up draft of air over the epicenter is more likely to be replenished by the relatively mild cold wind from Sub Himalayan region, as displayed by model VARSHA (Figure 15). All these aspects put weight-age in lowering the temperature leading to corresponding changes in RRI and finally to over horizon signal propagation.

The EQ caused modification in temperature can finally be modeled when the system passes through an isothermal and pseudo adiabatic irreversible process. The EQ induced temperature ( $\mathrm{Te}$ ) is the external energy say $\mathrm{Q}$ (isothermal), converted to work in moving the system (like wind etc.). The overall drainage of energy from the system cools the environment through adiabatic processes resulting to decreases of temperature from earthquake induced one Te to Tc. For growth of wind, the required temperature gradient can be well supported by the topography of the study environment.

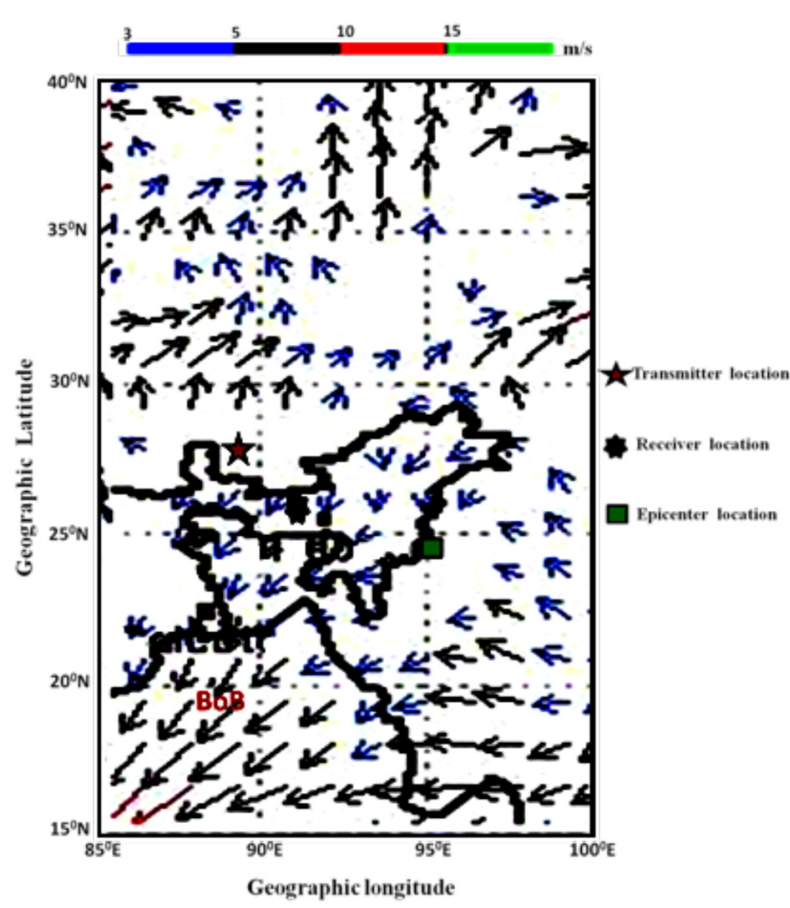

Figure 14. Speed $(\mathrm{m} / \mathrm{s})$ and direction of winds prevailing in the North East (NE) part of India during the month of January, as obtained from a mesoscale model VARSHA. Note that the North Easterly (NE) wind is most significant during this season. The position of transmitter, GU and the epicenter are marked in the figure. 


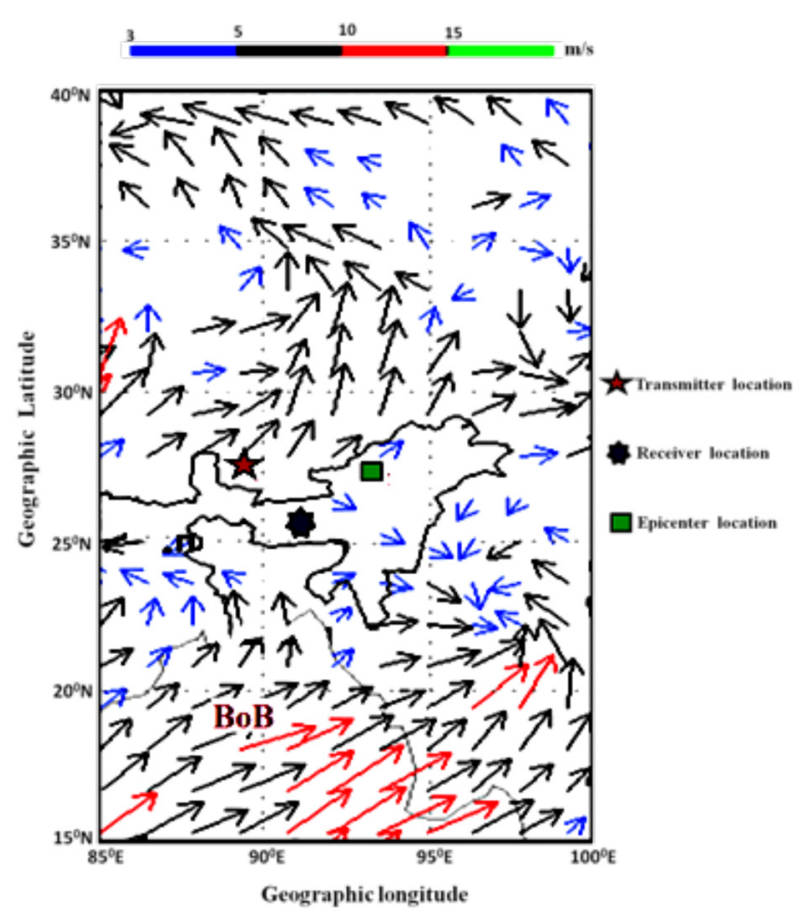

Figure 15. Speed $(\mathrm{m} / \mathrm{s})$ and direction of winds prevailing in the North East (NE) part of India during the month of October, as obtained from a mesoscale model VARSHA. Note that West-East wind along the sub Himalayan region is the only significant wind component in this season. The position of transmitter, GU and the epicenter are marked in the figure.

\section{Conclusion}

The phenomenon of trans-horizon LOS radio signal reception at GU from FM transmitter at Chukha, Bhutan, as presented here is due to EQ induced processes in the troposphere but not by ionospheric scattering or reflections. It is noted that this process is a consequence of increase in RRI gradient as a sequel to interception of at least a part of the link path by EQ preparatory radius. Further, the topography of the trans-receiver path is observed to play a significant role in such mode of reception. The paper reports a decrease in temperature (with a short initial increase) during an EQ, instead of an enhancement, as is the common observation. The drop in temperature is discussed with reference to the topography and prevailing wind components of the study environment, by a model system that encompasses an isothermal and pseudo adiabatic irreversible processes. However it is necessary to include humidity parameter in the model which will be our future exercise.

\section{References}

Alvan, H.V., F. Azad, Haydari and H. Omar (2012). Chlorophyll concentration and surface temperature changes associated with earthquakes, Nat. Hazards, 64, 691-706.

Bean, B.R., and L.P. Riggs (1959). Synoptic Variation of the Radio Refractive Index, Journal of Research of the National Bureau of Standards-D, Radio Propagation, 63D, 91-97.

Bean, B.R., and E.J. Duttan (1966), Radio meteorology, Dover Publications, US.

Cervone, G., M. Kafatos, D. Apoletani and R.P. Singh (2004). Wavelet maxima curves of surface latent heat flux associated with two recent major Greek earthquakes, Nat. Hazards Earth Sys., 4, 359-374.

Depueva, A.Kh., and Yu.Ya. Ruzhin (1995). Seismoionospheric fountain effect as analogue of active space experiment, Adv. Space Res., 15, 12-15.

Depueva, A.Kh., A. Mikhailov, M. Devi and A.K. Barbara (2007). Spatial and time variations in critical frequencies of the ionospheric F region above the zone of equatorial earthquake preparation, Geomagn. Aeronomy, 47, 129-133.

Devi, M., M.K. Barman, A.K. Barbara and A.Kh. Depueva (2001). Total electron content near anomaly crest as precursor of earthquake, Indian J. Radio Space, 30, 209-213.

Devi, M., A.K. Barbara and A. Depueva (2004). Association of total electron content and $\mathrm{f}_{\mathrm{o}} \mathrm{F} 2$ variations with earthquake events at the anomaly crest region, Annals of Geophysics, 47, 83-91.

Devi, M., A.K. Barbara, Yu.Ya. Ruzhin and A.Kh. Depueva (2007). Beyond the horizon propagation of VHF signals: atmospheric features and earthquake beyond the horizon propagation of VHF signals, atmospheric features and earthquake, Electronic journal, Investigated in Russia, 39, 1331-1340.

Devi, M., A.K. Barbara, P. Kashyap, A. Depueva, Y.Y. Ruzhin and V. Depuev (2010a). Earthquake time low latitude total electron content (TEC) variations and model based pattern: identification of earthquake induced atmospheric dynamics, Adv Geosci., 28, 69-84.

Devi, M., A.K. Barbara, A.H. Depueva, Y.Y. Ruzhin and V. Depuev (2010b). Anomalous Total Electron Content (TEC) and atmospheric refractivity prior to very strong China earthquake of May 2008, Int. J. Remote Sens., 3, 3589-3599.

Devi, M., A.J.D. Sarma,, S. Kalita, A.K. Barbara and A. Depueva (2011). Adoptive Techniques on Extraction of Pre-Seismic Parameters on Total Electron Content (TEC) at Anomaly Crest Stations Using GPS Data, Geomatics, Natural Hazards and Risk, 3, 193-206.

Devi, M., and A.K. Barbara (2012). Total Electron Content and Anomalous Appearance of GPS Satellites as Pointers to Epicenter Identification of Major Japan Earthquake of 2011, Positioning, 3, 7-12.

Devi, M., A.K. Barbara, Ya.Yu. Ruzhin and M. Hayakawa (2012). Over-the-Horizon Anomalous VHF Propagation and Earthquake Precursors, Surv. Geophys., 33, 1081-1106. 
Devi, M., A. Medhi, A.J.D. Sarma and A.K. Barbara (2013a). Growth and Inhibition of Equatorial Anomaly Prior to an Earthquake (EQ): Case Studies with Total Electron Content (TEC) Data for Major EQs of Japan 2011 and Indonesia 2012, Positioning, 4, 240-252.

Devi, M., A.K. Barbara, K. Oyama and C.H. Chen (2013b). Earthquake induced dynamics at the ionosphere in presence of magnetic storm, Adv. Space Res., 53, 609-618.

Dey, S., and R.P. Singh (2003). Surface latent heat flux as an earthquake precursor, Nat. Hazards Earth Sys., 3, 749-755.

Dolukhanov, M. (1971). Propagation of tropospheric waves, In: Propagation of radio waves, Mir, Moscow, 140-167.

Falodun, S.E., and M.O. Ajewole (2006). Radio refractive index in the lowest 100-m layer of the troposphere in Akure, South Western Nigeria, J. Atmos. Sol.-Terr. Phy., 68, 236-243.

Fukumoto, Y., M. Hayakawa and H. Yasuda (2002). Reception of over horizon FM signals associated with earthquake, In: M. Hayakawa and OA Molcghanov (eds.), Seismo electromagnetics: Lithosphere-Atmosphere-Ionosphere Coupling, TERAPUB, Tokyo, 263-266.

Glazier, E.V.D., and H.R.L. Lamont (1958). Transmission and Propagation, Edited by technical staff of Wireless World, published by Her Majesty Stationary Office, London.

Gokhberg, M.B., N.I. Gershenzon, I.L. Gufel'd, A.V. Kustov, V.A. Liperovskiy and S.S. Khusameddinov (1984). About possible effects of seismic origin electric fields on the ionosphere, Geomagn Aeron., 24, 217-222.

Goswami, H., M. Devi, S. Rambabu, A.K. Barbara and K. Prakash (2014). An analysis of the relation between precipitation and earthquake in the Indian region, Indian J. Radio Space, 43, 41-47.

Hall, M.P., and P.A. Bradley (1998). Troposphere and Ionosphere, section 13, In: Telecommunications Engineer's Reference Book, 2nd edition, Fraidoon Mazda (ed.) (Reed Educational and Professional Publishing Ltd.).

Harrison, R.G., K.L. Aplin and M.J. Rycroft (2010). Atmospheric electricity coupling between earthquake regions and the ionosphere, J. Atmos. Sol.-Terr. Phy., 72, 376-381.

Hayakawa, M., and O.A. Molchanov, eds. (2002). Seismo electromagnetics, lithosphere-atmosphere-ionosphere coupling, Terra Scientific Publishing Co., Tokyo.

Hayakawa, M., V.V. Surkov, Y. Fukumoto and N. Yonaiguch (2007). Characteristics of VHF over horizon signals possibly related to impending earthquakes and a mechanism of seismo-atmospheric perturbations, J. Atmos. Sol.-Terr. Phy., 69, 1057-1062.

Kushida, Y., and R. Kushida (1998). On a possibility earthquake forecast by radio observation in the VHF and band, RIKEN Rev, 19, 152-160.

Kushida, Y., and R. Kushida (2002). Possibility of earthquake forecast by radio observations in the VHF band, J. Atmos. Electr., 22, 239-255.

Lee, J.L. (1989). Dispersive microwave fading and lower atmospheric structure: An observational study, Radio Science, 24, 133-146.

Liu, J.Y., Y.I. Chen, Y.J. Chou, H.F. Tsai (2001). Variations of ionospheric total electron content during the Chi-Chi earthquake, Geophys. Res. Lett., 28, 1383-1386.

Moriya, T., T. Mogi and M. Takada (2010). Anomalous pre-seismic transmission of VHF-band radio waves resulting from large earthquakes, and its statistical relationship to magnitude of impending earthquakes, Geophys. J. Int., 180, 858-870.

Onoe, M., M. Hiraj and S. Niwa (1958). Results of experiment of Long distance overland propagation of ultra-short waves, J. Radio Research Labs, Japan, 5, 79.

Ouzounov, D., D. Liu, C. Kang, G. Cervone, M. Kafatos and P. Taylor (2007). Outgoing long wave radiation variability from IR satellite data prior to major earthquakes, Tectonophysics, 431, 211-220.

Parrot, M., J.J. Berthelier, J.P. Lebreton, R. Treumann and J.L. Rauch (2008). DEMETER observations of EM emissions related to thunderstorms, Planetary Atmospheric Electricity Space Sciences Series of ISSI, 137, 511-519.

Parrot, M., J.A. Sauvaud, S. Soula, J.L. Pinçon and O. van der Velde (2013). Ionospheric density perturbations recorded by DEMETER above intense thunderstorms, J. Geophys. Res., Space Physics, 118, 1-8.

Pilipenko, V., S. Shalimov, S. Uyeda and S. Tanaka (2001). Possible mechanism of the over-horizon reception of FM radio waves during earthquake preparation period, Pro. Japan Acad., 77, Ser. B, 125-130.

Piša, D., F. Němec, O. Santolík, M. Parrot and M. Rycroft (2013). Additional attenuation of natural VLF electromagnetic waves observed by the DEMETER spacecraft resulting from preseismic activity, J. Geophys. Res., Space Physics, 118, 5286-5295.

Priestley, J.T. and R.J. Hill (1985). Measuring High-Frequency Refractive Index in the Surface Layer, Journal Atmos. Ocean. Tech., 2, 233-251.

Qiang, Z. (1997). Thermal infrared anomaly precursor of earthquake, Pure Appl. Geophys., 149, 159-170.

Sakai, K., H. Higasa and S. Shimakura (2003). Observations of Anomaly in Oversea Long distance Prop- 
agation of TV broadcasting waves, IEEJ Transactions on Electronics, Information and Systems, 123, 167-168.

Serdega, D., and G. Ivanovs (2007). Refraction seasonal variation and the influence on to $\mathrm{GHz}$ range microwaves availability, Electronics and Electrical Engineering-Kaunas Technologija, 78, 39-42.

Sheer, P.E. (1961). Airborne Refractive Index at $150 \mathrm{mb}$, J. Meteorol., 18, 494-500.

Singh, R.P., G. Cervone, V.P. Singh and M. Kafatos (2007). Generic precursors to coastal earthquakes: Inferences from Denali fault earthquake, Tectonophysics, 431, 231-240.

Singh, R.P., W. Mehdi and M. Sharma (2010). Complementary nature of surface and atmospheric parameters associated with Haiti earthquake of 12 January 2010, Nat. Hazards Earth Sys., 10, 1299-1305.

Smith Jr., E.K., and S. Weintraub (1953). The constants in the equation for atmospheric refractive index at radio frequencies, Journal of Research of the Notional Bureau of Standards, 50, 39-51.

Sorokin, V.M., A.K. Yaschenko and M. Hayakawa (2014). Scattering of VHF transmitter signals by seismic-related electric discharges in the troposphere, J. Atmos. Sol.-Terr. Phy., 109, 15-21.

Takano, T., K. Sakai, I. Nagashima, H. Nakata, H. Akaike, S. Ujigawa, H. Higasa and S. Shimakura (2004). Broadband observations of propagation anomaly of VHF waves transmitted from overseas broadcasting stations, Proc. International Symp on Ant and Prop. IEEE, 0-7803-8404-0/04.

Tronin, A. (2000). Thermal IR satellite sensor data application for earthquake research in China, Int. J. Remote Sens., 16, 3169-3177.

Tronin, A. (2002). Atmosphere-Lithosphere coupling. Thermal anomalies on the Earth's surface in seismic process, In: M. Hayakawa and O.A. Molchanov (eds.), Seismo electromagnetics: lithosphere-atmosphere-ionosphere coupling, TERRAPUB, Tokyo, 173-176.

Valma, E., E.M. Tamosiunaite, S. Tamosiunas, M. Tamosiuniene and M. Zilinskas (2011). Variation of Radio Refractivity with Height above Ground, Electronics and electrical Engineering, 5 (111), 23-26.

Webster, A.R., and W.I. Lam (1980). Microwave angleof-arrival measurements under anomalous tropospheric propagation conditions, Annales des Télécommunications, 35, 474-478.

Yasuda, Y., Y. Ida, T. Goto and M. Hayakawa (2009). Interferometric direction finding of over horizon VHF transmitter signal and natural VHF radio emission possibly associated with earthquakes, Radio Science, 44, 1-10.
Corresponding author: Minakshi Devi, Gauhati University, Department of Physics, Guwahati, India; email: md555gu@gmail.com.

(C) 2015 by the Istituto Nazionale di Geofisica e Vulcanologia. All rights reserved. 